\title{
MAS Probe Correction Method
}

National Cancer Institute

\section{Source}

National Cancer Institute. MAS Probe Correction Method. NCI Thesaurus. Code C64231.

Correct perfect match (PM) probe levels using the ideal mismatch algorithm. Defined in the documents available at http://bioconductor.org/packages/1.9/bioc/html/affy.html. 